\title{
An integrated bioinformatical analysis to evaluate the role of KIF4A as a prognostic biomarker for breast cancer
}

This article was published in the following Dove Press journal:

OncoTargets and Therapy

\author{
Dan Xue, ${ }^{1, *}$ Pu Cheng, ${ }^{2, *}$ \\ Mengjiao Han, ${ }^{3}$ Xiyong Liu, ${ }^{4,5}$ \\ Lijun Xue, ${ }^{6}$ Chenyi Ye, ${ }^{7}$ \\ Ke Wang, ${ }^{8}$ Jian Huang ${ }^{8,9}$ \\ 'Department of Plastic Surgery, Second \\ Affiliated Hospital, Zhejiang University \\ School of Medicine, Hangzhou, China; \\ ${ }^{2}$ Department of Gynaecology, Second \\ Affiliated Hospital of Zhejiang University \\ School of Medicine, Hangzhou, China; \\ ${ }^{3}$ Department of Medical Oncology, Key \\ Laboratory of Biotherapy in Zhejiang, Sir \\ Run Run Shaw Hospital, Medical School \\ of Zhejiang University, Hangzhou, China; \\ ${ }^{4}$ Biomarker Development, California Cancer \\ Institute, Temple City, CA, USA; ${ }^{5}$ School of \\ Medicine, Taipei Medical University, Taipei, \\ Taiwan, Republic of China; ${ }^{6}$ Department of \\ Pathology, Loma Linda University Medical \\ Center, Loma Linda, CA, USA; ' ${ }^{7}$ epartment \\ of Orthopaedics, Second Affiliated Hospital, \\ Zhejiang University School of Medicine, \\ Hangzhou, China; ${ }^{8}$ Department of Surgical \\ Oncology, Second Affiliated Hospital of \\ Zhejiang University School of Medicine, \\ Hangzhou, China; ' $\mathrm{G}$ astroenterology \\ Institute, Zhejiang University School of \\ Medicine, Hangzhou, China \\ *These authors contributed equally \\ to this work
}

Correspondence: Jian Huang

Department of Surgical Oncology, Second Affiliated Hospital of Zhejiang University School of Medicine, No. 88, Jiefang Road, Shangcheng

District, Hangzhou, China

Tel/Fax +86 57187784642

Email drhuangjian@zju.edu.cn
Purpose: The aim of this study was to investigate the diagnostic and prognostic value of human kinesin family member 4A (KIF4A) as an effective biomarker for breast cancer.

Materials and methods: Cancer Genome Atlas data and 12 independent public breast cancer microarray data sets were downloaded and analyzed using individual and pooled approaches.

Results: The results of our study revealed a strong and positive correlation between KIF4A expression and malignant features of breast cancer. KIF4A had a strong prognostic value in both ER-positive and ER-negative breast cancers comparable to or even better than tumor size, lymph node invasion, and Elston grade. We also found that KIF4A might be the target gene of microRNA-335, which can suppress KIF4A expression by targeting the 3'-untranslated region of its mRNA.

Conclusion: KIF4A might serve as a robust prognostic predictor for breast cancer. Targeting KIF4A activity could be a promising therapeutic option in breast cancer treatment.

Keywords: breast cancer, KIF4A, microarray, microRNA, prognosis

\section{Introduction}

Breast cancer is one of the most common malignant tumors which accounts for the second leading cause of mortality for women worldwide. ${ }^{1}$ The development of screening methods and therapeutic approaches has considerably improved the survival for patients with breast cancer in recent years. ${ }^{2-4}$ However, tumor heterogeneity remains a great clinical challenge which leads to great individual differences in the outcome of breast cancer treatments. Currently, several genetic predictors have been applied to the clinical diagnosis and treatment of breast cancer, such as wound-response gene signature, ${ }^{5} 21$-gene recurrence score, ${ }^{6}$ and 70 -gene signature. ${ }^{7}$ Nevertheless, all these methods lack specificity and may impose additional financial burden on the patients. Thus, there is a pressing need for more specific and economical biomarkers to predict prognosis and develop better therapeutic strategies of breast cancer.

Human kinesin family member 4A (KIF4A) is a $140-\mathrm{kD}$ protein which plays a critical role in multiple cellular processes, mainly including chromosome condensation and segregation, middle-spindle formation, and cytokinesis during mitotic division. ${ }^{8-11}$ Recently, it has become apparent that KIF4A plays an essential role in cancer development and progression. Studies have shown that KIF4A served as a potential contributor of several malignant tumors, such as lung cancer, ${ }^{12,13}$ breast cancer, ${ }^{14}$ cervical cancer, ${ }^{15}$ hepatocellular carcinoma, ${ }^{16}$ and oral cancer, ${ }^{17,18}$ while in gastric cancer, KIF4A was observed to inhibit tumor cell growth. ${ }^{19}$ As for breast cancer, data from the study by 
Wu et al indicated that KIF4A could modulate the Rad51 pathway by interacting with the breast cancer susceptibility gene BRCA2. ${ }^{20}$ However, the exact role and underlining molecular mechanisms of KIF4A in breast cancer remain unclear.

MicroRNAs constitute a class of noncoding small RNAs ranging from 20 to 24 nucleotides in length. They widely exist in eukaryotes and regulate gene expression at the posttranscriptional level by binding to the $3^{\prime}$-untranslated region (UTR) of their target gene mRNAs, leading to either translational repression or mRNA degradation. ${ }^{21-24}$ A single microRNA can target multiple mRNAs while individual mRNAs may be regulated by different microRNAs simultaneously, resulting in a complex regulatory network. ${ }^{22,25}$ MicroRNAs were proved to play key roles in the modulation of various biological processes. ${ }^{23,26}$ A large body of evidence has indicated that there is a direct link between microRNA function and oncogenesis, ${ }^{27,28}$ serving as both promoter and suppressor to regulate the progression of different cancers. ${ }^{29-31} \mathrm{Up}$ to now, the microRNAs targeting KIF4A remain unknown.

The main aim of this study is to investigate the diagnostic and prognostic value of KIF4A as an effective biomarker for breast cancer. The Cancer Genome Atlas (TCGA) data sets and 12 independent public breast cancer microarray data sets were downloaded and analyzed using individual and pooled approaches. The relationships between the expression of KIF4A and the clinicopathological characteristics of breast cancer were then evaluated. The results indicated that KIF4A expression was positively correlated with cancer malignancy. In addition, KIF4A had a strong prognostic value in both estrogen receptor (ER)-positive and ER-negative breast cancers. We also found that KIF4A might be the target gene of microRNA-335 (miR-335), which was confirmed by the dual luciferase reporter assay.

\section{Materials and methods Microarray data sets acquisition and processing}

Human breast tissue gene expression profile data sets with corresponding clinical and follow-up information were downloaded from the publicly available Gene Expression Omnibus (GEO) database (www.ebi.ac.uk/arrayexpress) $)^{32}$ and TCGA database (https://cancergenome.nih.gov/). ${ }^{33}$ Besides TCGA data sets, 12 independent breast cancer microarray data sets were chosen for the present study as follows: GSE7390, ${ }^{34}$ GSE1456, ${ }^{35}$ GSE2034, ${ }^{36}$ GSE4922, ${ }^{37}$ NKI, ${ }^{38}$ GSE10885, ${ }^{39}$ GSE24450,${ }^{40}$ GSE22226, ${ }^{41}$ GSE25066, ${ }^{42}$ GSE53031, ${ }^{43}$ GSE58812, ${ }^{44}$ and GSE22220. ${ }^{45}$ Demographic distribution of KIF4A for GEO and TCGA data sets is presented in Tables 1 and 2, respectively. All data sets were used to evaluate the clinical significance of KIF4A in breast cancer and the GSE22220 data set was used to investigate microRNAs possibly regulating KIF4A expression. In order to normalize the mRNA and microRNA expression levels, we re-stratified patients into four subgroups (Q1, Q2, Q3, and Q4) based on the percentile for each data set. The re-stratified data sets were then integrated into a new data set for pooled analysis. Expression levels less than the median value were defined as KIF4A low (Q1 + Q2) while expression levels greater than or equal to the median were regarded as KIF4A high (Q3 + Q4).

\section{Gene set enrichment analysis (GSEA)}

GSEA software version 2.0.13 was used to investigate the clinical relevance and biological effects of KIF4A according to the protocol described in a previous study. ${ }^{46}$ Each data set and the corresponding phenotype label were loaded into the GSEA software. The gene sets were acquired from the Board Institute website. The number of permutations was set to 1,000 , and the phenotype label was based on KIF4A (218355_at) expression levels. The signal-to-noise ratio was calculated and ranked-list metric was then generated.

Table I Demographic distribution of KIF4A in GEO data sets

\begin{tabular}{|c|c|c|c|}
\hline \multirow[t]{2}{*}{ Variables } & \multicolumn{3}{|l|}{ KIF4A } \\
\hline & High (\%) & Low (\%) & $P$-value** \\
\hline Age (years) & & & 0.0629 \\
\hline$<50$ & $263(52.5)$ & $238(47.5)$ & \\
\hline$\geq 50$ & $299(45.9)$ & $229(53.6)$ & \\
\hline Grade & & & $<0.0001$ \\
\hline $\mathrm{I}=$ well & $48(22.5)$ & $165(77.5)$ & \\
\hline $2=\bmod$ & $198(42.4)$ & $269(57.6)$ & \\
\hline $3=$ poor & $299(71.7)$ & I I 8 (28.3) & \\
\hline ER & & & $<0.0001$ \\
\hline Negative & $285(66.1)$ & 146 (33.9) & \\
\hline Positive & $397(42.6)$ & $536(57.5)$ & \\
\hline Tumor size & & & $<0.0001$ \\
\hline$<2$ & $83(38.3)$ & $447(51.26)$ & \\
\hline$\geq 2$ & $174(52.4)$ & $158(47.6)$ & \\
\hline Lymph node status & & & 0.2625 \\
\hline Negative & $426(48.8)$ & $447(5 \mid .2)$ & \\
\hline Positive & $174(52.4)$ & I58 (47.6) & \\
\hline Molecular subtype & & & $<0.0001$ \\
\hline Luminal A & 31 (20.4) & $|2|(79.6)$ & \\
\hline Luminal B & $98(72.6)$ & $37(27.4)$ & \\
\hline HER2+ & $60(68.2)$ & $28(31.8)$ & \\
\hline Basal-like & I I 8 (77.6) & $34(22.4)$ & \\
\hline Normal-like & $18(15.0)$ & $102(85.0)$ & \\
\hline
\end{tabular}

Notes: There are 928, I,097, I,364, 630, I,205, and 67। cases in age, grade, ER, tumor size, lymph node status, and molecular subtype. Statistical significance, $* * p<0.05$. Abbreviations: ER, estrogen receptor; HER2, human epidermal growth factor receptor 2; KIF4A, human kinesin family member 4A; GEO, Gene Expression Omnibus; mod, moderate. 
Table 2 Demographic distribution of KIF4A in TCGA data sets

\begin{tabular}{|c|c|c|c|}
\hline \multirow[t]{2}{*}{ Variables } & \multicolumn{3}{|l|}{ KIF4A } \\
\hline & High (\%) & Low (\%) & $P$-value** \\
\hline Age (years) & & & 0.0035 \\
\hline$<50$ & $309(55.4)$ & $249(44.6)$ & \\
\hline$\geq 50$ & $905(48.3)$ & $967(51.7)$ & \\
\hline Grade & & & $<0.0001$ \\
\hline$I=$ well & $20(12.1)$ & I45 (87.9) & \\
\hline $2=\bmod$ & $26 I(35.2)$ & $480(64.8)$ & \\
\hline $3=$ poor & 647 (69.9) & $279(30.1)$ & \\
\hline ER & & & $<0.0001$ \\
\hline Negative & $422(36.7)$ & $124(63.3)$ & \\
\hline Positive & $777(42.1)$ & $\mathrm{I}, 070(57.9)$ & \\
\hline Tumor size & & & $<0.0001$ \\
\hline$<2$ & $249(42.0)$ & $344(58.0)$ & \\
\hline$\geq 2$ & $693(53.6)$ & $600(46.4)$ & \\
\hline Tumor stage & & & $<0.0001$ \\
\hline TO & $3(75.0)$ & I (25.0) & \\
\hline $\mathrm{TI}$ & $237(39.0)$ & $370(61.0)$ & \\
\hline T2 & $595(53.5)$ & $517(46.5)$ & \\
\hline $\mathrm{T} 3$ & $98(56.0)$ & $77(44.0)$ & \\
\hline $\mathrm{T} 4$ & $16(55.2)$ & I $3(44.8)$ & \\
\hline Lymph node status & & & 0.2084 \\
\hline Negative & $123(48.2)$ & $132(5 \mid .8)$ & \\
\hline Positive & $136(52.3)$ & $124(47.7)$ & \\
\hline Molecular subtype & & & $<0.0001$ \\
\hline Luminal A & $128(18.9)$ & $55 I(8 I . I)$ & \\
\hline Luminal B & 357 (77.4) & $104(22.6)$ & \\
\hline HER2+ & I6I (73.2) & $59(26.8)$ & \\
\hline Basal-like & $182(9 \mid .5)$ & $17(8.5)$ & \\
\hline Normal-like & $27(19.3)$ & II 3 (80.7) & \\
\hline Claudin-low & $94(47.2)$ & $105(52.8)$ & \\
\hline Chemotherapy & & & $<0.0001$ \\
\hline No & $683(45.3)$ & $825(54.7)$ & \\
\hline Yes & $269(67.9)$ & $127(32.1)$ & \\
\hline
\end{tabular}

Notes: Number of cases - age: 2,430; grade: I,832; ER: 2,393; tumor size: I,886; tumor stage: 1,927; lymph node status: 515; molecular subtype: 1,898; chemotherapy: 1,904. Statistical significance, $* * P<0.05$.

Abbreviations: ER, estrogen receptor; HER2, human epidermal growth factor receptor 2; KIF4A, human kinesin family member 4A; mod, moderate; TCGA, The Cancer Genome Atlas.

\section{Prediction of microRNAs regulating KIF4A expression}

The GSE22220 data set was used to identify microRNAs independently associated with KIF4A expression in breast cancer. miRanda algorithm (www.microrna.org) was applied to predict microRNAs with possible binding sites on KIF4A mRNA. MicroRNAs shared by two methods were chosen for the subsequent analysis and experiment.

\section{Dual luciferase reporter assay}

Dual luciferase reporter assay was performed to predict the direct binding of miR-335 to the target gene KIF4A. The pmirGLO Dual Luciferase MicroRNA Target Expression Plasmid was purchased from Promega Corporation (Fitchburg, WI,
USA). The recombinant plasmids were constructed by inserting either the exactly matched sequence or a mutant version of KIF4A 3'-UTR into the pmirGLO vector. For the luciferase reporter assay, HEK293T cells were seeded and grown as monolayers in six-well plates. Cells were transfected with the miR-335 pmirGLO constructs and miR-335 using Lipofectamine 3000 (Thermo Fisher Scientific, Waltham, MA, USA). Scrambled RNA was used as a negative control. The cells were assayed using the Dual-Glo luciferase assay kit (Promega Corporation) 24 hours after transfection. Normalized luciferase activity for each construct was compared to that of the no-insert positive control. For each transfection, luciferase activity was averaged from four replicates.

\section{Data management and statistical analysis}

The gene expression profile database was downloaded, converted, constructed, and managed by MS Excel. Statistical analysis was performed using JMP 10.0 software (SAS Institute Inc, Cary, NC, USA). Categorical variables were compared using $\chi^{2}$ analysis, Fisher's exact, or the binomial tests of proportions. Continuous data were compared using independent $t$-tests. Kaplan-Meier analysis and Cox proportional hazard models were applied for survival analysis. Multivariate Cox proportional hazards regression model was adopted to adjust for covariate effects, and stratification analysis was used to reduce the potential confounding effect on the estimation of hazard ratio (HR). Missing data were coded and excluded from the analysis. $P<0.05$ was considered to indicate statistical significance.

\section{Results}

\section{The expression of KIF4A associates with the aggressiveness of breast cancer}

To investigate the clinical relevance of KIF4A expression, 12 independent public breast cancer microarray data sets were analyzed individually and in a pooled approach. Results showed that the mRNA expression level of KIF4A was significantly related to tumor size and grade, but not lymph node invasion in the pooled data set (Figure 1A). In the Pawitan set (GSE1456), KIF4A expression was significantly higher in basal-like breast cancers which were known as the molecular subtype with poorest prognosis (Figure 1B). A further GSEA indicated that KIF4A-high phenotype significantly enriched the gene signatures related to high tumor grade in the Pawitan set, with the normalized enrichment score at 2.73 (Figure 1C). The overall results for the KIF4A enriched gene signatures presented in Figure 1D suggested that KIF4A was intimately associated with breast cancer susceptibility, invasion, metastasis, and relapse. Taken together, these results suggested that high expression 
A

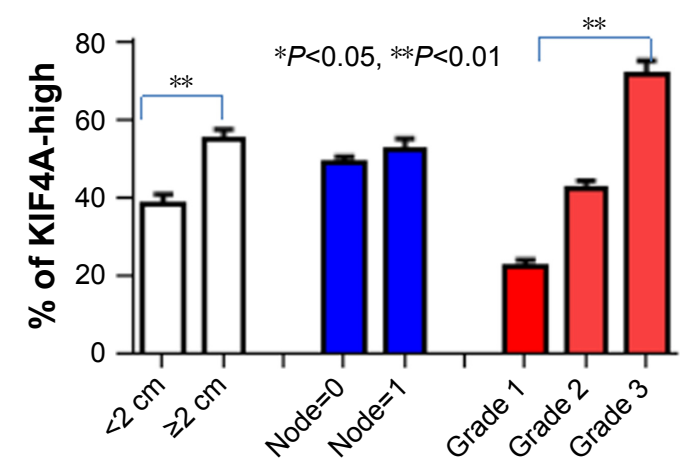

B

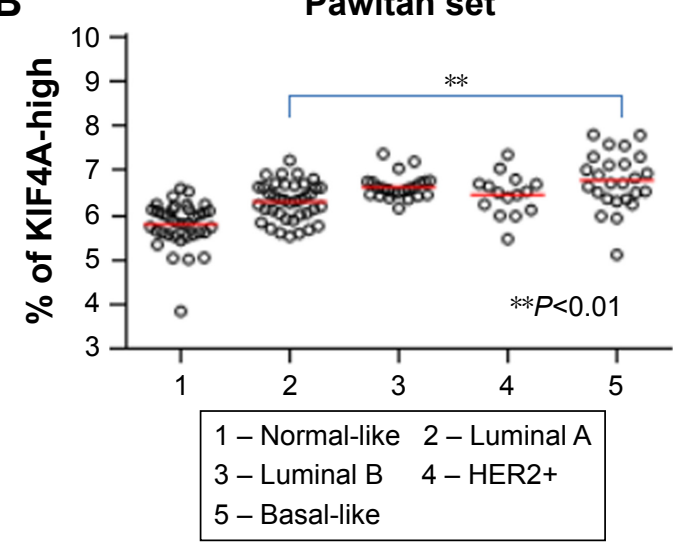

C

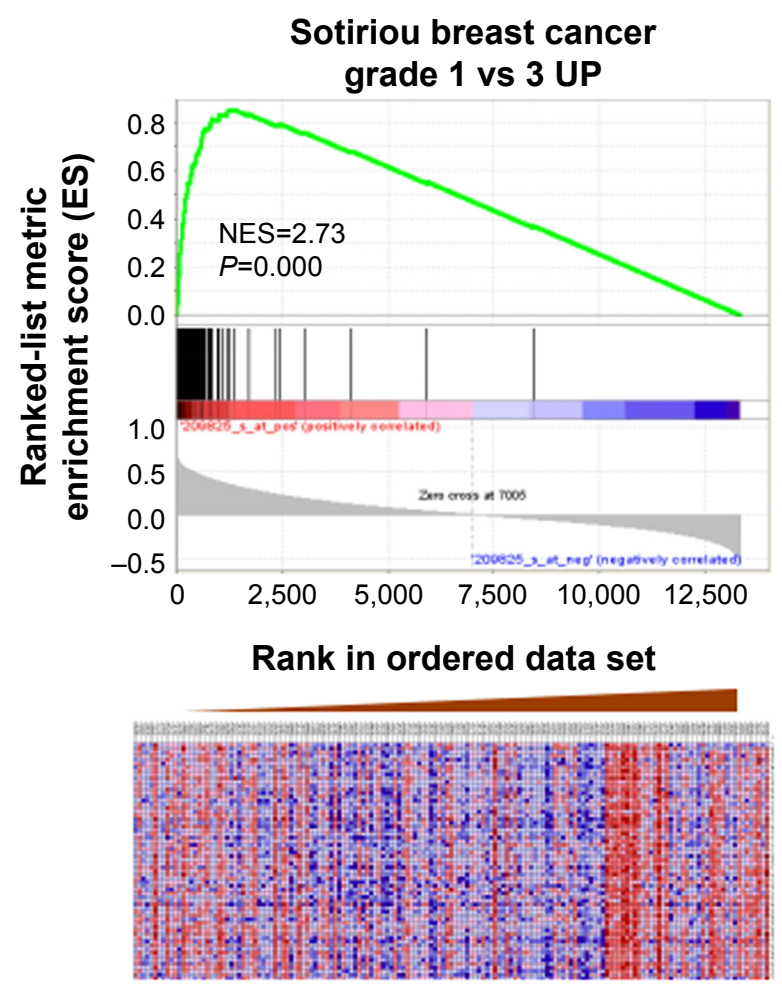

D

PUJANA_BREAST_CANCER_LIT_LNT_NETWORK PUJANA_BREAST_CANCER_WITH_BRCA1_MUTATED... FARMER_BREAST_CANCER_CLUSTER_2 GINESTIER_BREAST_CANCER_ZNF217_AMPLIFIED_DN VANTVEER_BREAST_CANCER_ESR1_DN HEDENFALK_BREAST_CANCER_BRCA1_VS_BRCA2 WANG_METASTASIS_OF_BREAST_CANCER_ESR1_UP TOMIDA_METASTASIS_UP WINNEPENNINCKX_MELANOMA_METASTASIS_DN FARMER_BREAST_CANCER_CLUSTER_5 TURASHVILI_BREAST_LOBULAR_CARCINOMA_VS_D... NADERI_BREAST_CANCER_PROGNOSIS_DN SMID_BREAST_CANCER_RELAPSE_IN_BONE_UP TURASHVILI_BREAST_LOBULAR_CARCINOMA_VS_L... VANTVEER_BREAST_CANCER_ESR1_UP LIEN_BREAST_CARCINOMA_METAPLASTIC POOLA_INVASIVE_BREAST_CANCER_DN SOTIRIOU_BREAST_CANCER_GRADE_1_VS_3_DN
NES

Rank in ordered data set

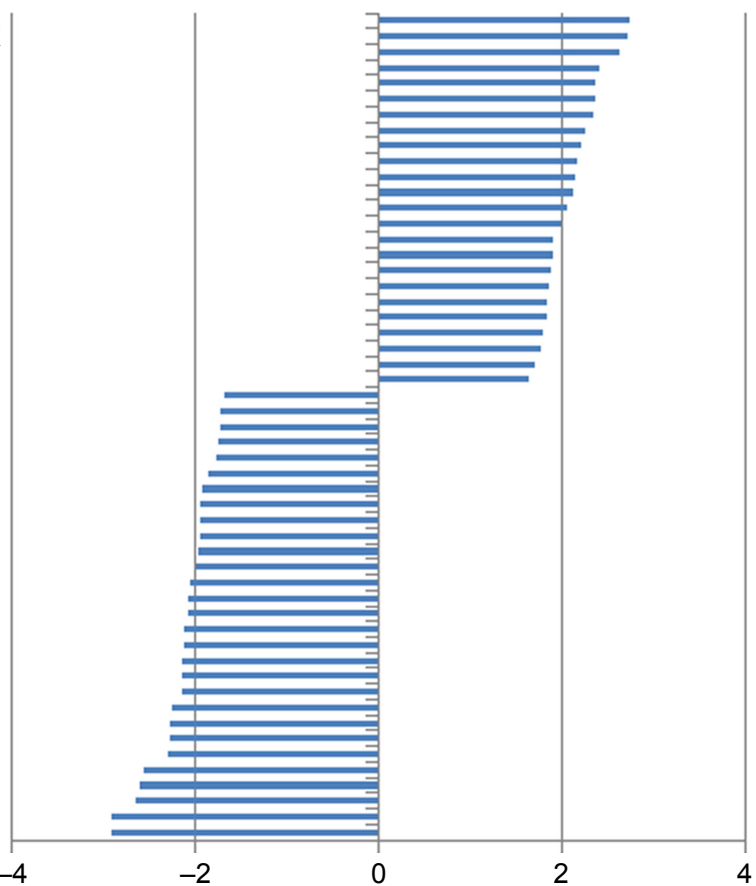

Figure I The expression of KIF4A associates with the aggressiveness of breast cancer. (A) mRNA expression level of KIF4A was significantly related to tumor size and grade, but not lymph node invasion in the pooled data set. (B) KIF4A expression was significantly higher in basal-like breast cancers. (C) GSEA indicated that KIF4A-high phenotype significantly enriched the gene signatures related to high tumor grade in the Pawitan set. (D) The overall results for the KIF4A enriched gene signatures.

Abbreviations: KIF4A, human kinesin family member 4A; GSEA, gene set enrichment analysis; NES, normalized enrichment score; HER2, human epidermal growth factor receptor 2 . 
of KIF4A was significantly associated with aggressiveness of breast cancer.

\section{Prognostic significance of KIF4A for breast cancer}

Survival analysis was performed on TCGA data sets as well as 12 GEO data sets. Cases of each data set were recategorized into four subgroups (Q1, Q2, Q3, and Q4) based

A

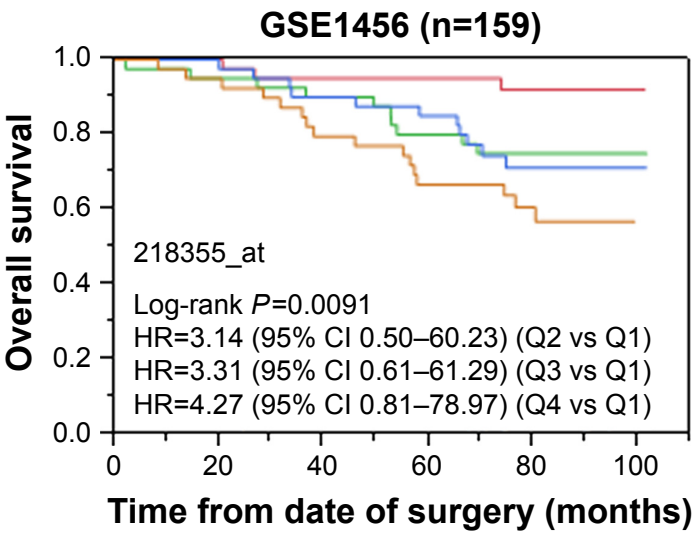

mRNA

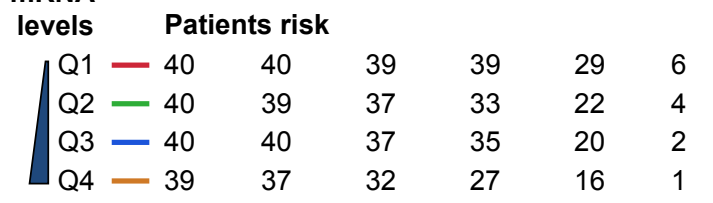

C

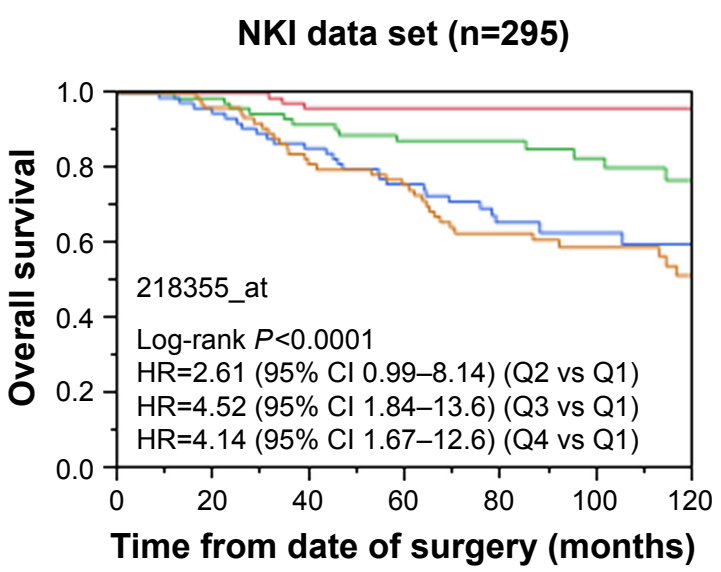

mRNA

levels Patients risk

$\begin{array}{lllllll}\mathrm{Q} 1-73 & 73 & 70 & 67 & 53 & 40 & 30 \\ \mathrm{Q} 2-73 & 72 & 63 & 59 & 43 & 32 & 22 \\ \mathrm{Q} 3-74 & 71 & 64 & 53 & 34 & 21 & 14 \\ \mathrm{Q} 4-75 & 72 & 60 & 56 & 38 & 30 & 19\end{array}$

Figure 2 (Continued) on the percentile of KIF4A expression. The lowest expression subgroup, Q1, was set as the reference category for calculation of the HR. Univariate and multivariate Cox proportional hazard analyses were conducted for each data set. We found that higher expression of KIF4A was significantly associated with poor survival on both overall survival (OS) and progressionfree survival (PFS) in the Pawitan set (Figure 2A and B) and NKI set (Figure 2C and D). As KIF4A expression improved,

B

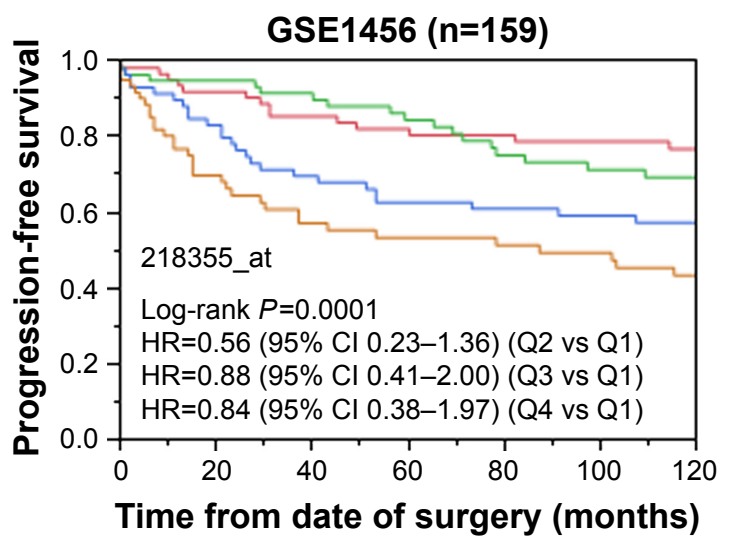

mRNA

levels Patients risk

$\begin{array}{lllllll}\mathrm{Q} 1-64 & 59 & 53 & 49 & 47 & 42 & 37 \\ \mathrm{Q} 2-61 & 58 & 54 & 48 & 40 & 37 & 32 \\ \mathrm{Q} 3-60 & 51 & 41 & 37 & 35 & 33 & 27 \\ \mathrm{Q} 4-64 & 39 & 31 & 28 & 27 & 25 & 22\end{array}$

D

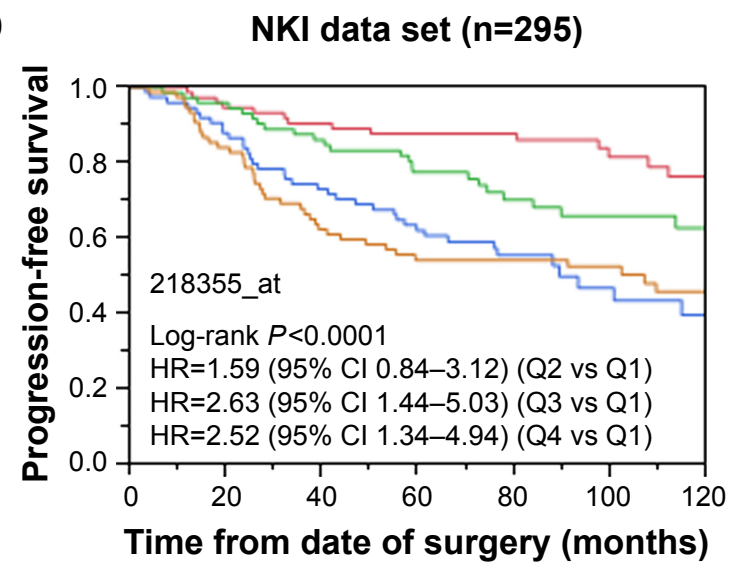

mRNA

levels Patients risk

\begin{tabular}{|lllllll}
$\mathrm{Q} 1-73$ & 70 & 66 & 64 & 52 & 37 & 27 \\
$\mathrm{Q} 2-73$ & 70 & 61 & 54 & 36 & 27 & 18 \\
$\mathrm{Q} 3-74$ & 66 & 55 & 44 & 24 & 14 & 9 \\
$\mathrm{Q} 4-75$ & 63 & 47 & 41 & 34 & 28 & 18
\end{tabular}


E

GEO pooled data set $(n=1,237)$

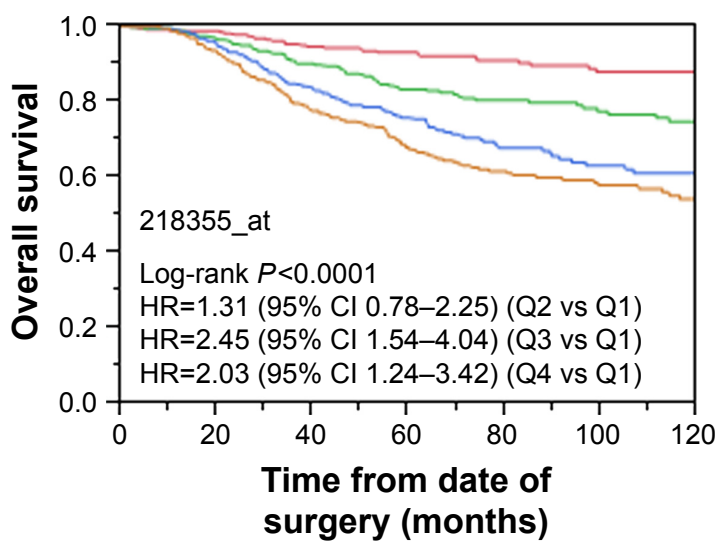

F GEO pooled data set $(\mathrm{n}=\mathbf{2 , 1 3 7 )}$

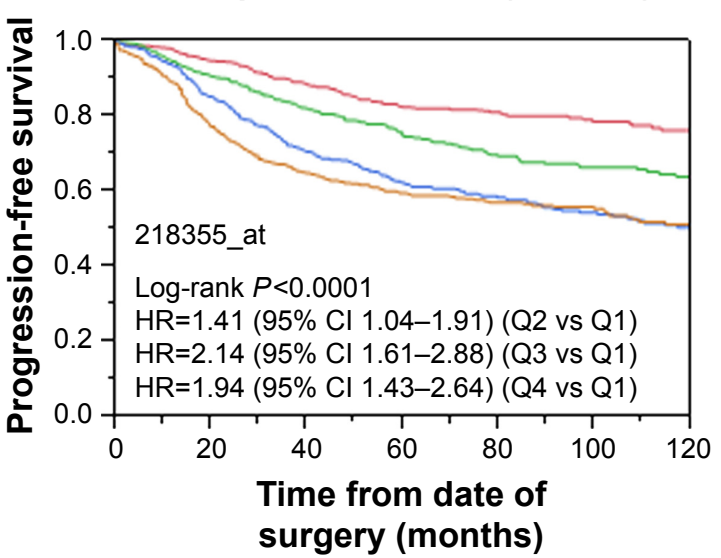

mRNA

levels Patients risk

$\mid \begin{array}{lllllll}\mathrm{Q} 1-310 & 293 & 255 & 204 & 149 & 100 & 79 \\ \mathrm{Q} 2-309 & 278 & 239 & 193 & 133 & 95 & 68 \\ \mathrm{Q} 3-308 & 283 & 239 & 183 & 118 & 67 & 49 \\ \mathrm{Q} 4-310 & 282 & 222 & 163 & 117 & 77 & 53\end{array}$
mRNA

levels Patients risk

$\begin{array}{lllllll}\mathrm{Q} 1-535 & 491 & 402 & 291 & 234 & 160 & 114 \\ \mathrm{Q} 2-534 & 460 & 360 & 264 & 193 & 126 & 91 \\ \mathrm{Q} 3-531 & 437 & 332 & 227 & 168 & 108 & 71 \\ \mathrm{Q} 4-537 & 401 & 292 & 214 & 168 & 123 & 83\end{array}$

Figure 2 The prognostic significance of KIF4A in breast cancer patients. Overall survival analysis for KIF4A in (A) GSEI456 data set, (C) NKI data set, (E) GEO pooled data set with overall survival information. Progression-free survival analysis for KIF4A in (B) GSEI456 data set, (D) NKI data set, (F) GEO pooled data set with progression-free survival information.

Abbreviations: KIF4A, human kinesin family member 4A; GEO, Gene Expression Omnibus; HR, hazard ratio.

OS and PFS were gradually decreased, in almost in a dosedependent manner. Similar results were observed in the GEO pooled analysis as well (Figure 2E and F), with an adjusted HR of 1.31 in Q2 (95\% CI: 0.78-2.25), 2.45 in Q3 (95\% CI: $1.54-4.04)$, and 2.03 in Q4 (95\% CI: 1.24-3.42) for OS and 1.41 in Q2 (95\% CI: 1.04-1.91), 2.14 in Q3 (95\% CI: 1.61-2.88), and 1.94 in Q4 (95\% CI: 1.43-2.64) for PFS. As for the TCGA pooled analysis, statistical significance was only observed in OS. Detailed analytical results for each data set are listed in Tables 3 and 4. Further stratified analysis of the GEO pooled data suggested that KIF4A expression levels were significantly associated with poor OS and PFS in both ER-positive (Figure 3A and B) and ER-negative subtypes (Figure 3C and D). However, a more remarkable dosedependent fashion was observed in ER-positive subtypes than ER-negative subtypes. In TCGA data sets, KIF4A expression demonstrated a notable effect on OS in ER-positive breast cancer only (data not shown). Moreover, as displayed in Figure 4D and E, the prognostic performance of KIF4A was comparable to or even better than tumor size, lymph node invasion, and Elston grade in both ER-positive and ER-negative breast cancers. All these findings suggested that KIF4A could serve as a strong prognostic predictor for breast cancer.

\section{miR-335 is a possible regulator of KIF4A}

In order to gain a better understanding of the clinicobiological role of KIF4A in breast cancer, we next looked for its potential regulators. MicroRNAs independently associated with KIF4A expression in breast cancer were identified by analyzing the GSE22220 data set. miRanda algorithm was applied to predict microRNAs with possible binding sites on KIF4A mRNA. Finally, two microRNAs shared by both methods were discovered: miR-335 and miR-411 (Figure 5A). The predicted binding sequence of these two microRNAs and KIF4A mRNA $3^{\prime}$-UTR is presented in Figure 5B, along with the thermodynamic stability score (miRNA support vector regression [mirSVR]) and sequence conservation score (PhastCons). As illustrated in Figure 5C, the level of KIF4A in breast cancer was negatively correlated with miR-335 and miR-411 expression. Further stratified analysis of the GSE22220 data set demonstrated that the expression of miR-335, but not miR-411, was significantly associated with better PFS in a dose-dependent manner (Figure 4A and B). Dual luciferase reporter assay was then performed to study the direct binding and influence on the transcript activity of miR-335 on the target gene KIF4A. The results indicated that miR-335 suppressed KIF4A expression by targeting the 3'-UTR of KIF4A mRNA (Figure 4C). Of greater importance, as with KIF4A, the prognostic performance of miR-335 was comparable with tumor size and lymph node involvement, better than Elston grade in ER-positive breast cancer (Figure 4D). Although no prognostic significance was found for miR-335 expression in ER-negative subgroups, there was an increasing trend in reciprocal HR values as microRNA levels increased (Figure 4E). 
Table 3 Univariate and multivariate analyses for KIF4A and survival in GEO data sets

\begin{tabular}{|c|c|c|c|c|}
\hline \multirow[t]{2}{*}{ Data set } & \multicolumn{2}{|l|}{ Overall survival } & \multicolumn{2}{|c|}{ Progression-free survival } \\
\hline & HR (95\% Cl) & Adjusted HR (95\% CI)* & HR (95\% Cl) & Adjusted HR $(95 \% \mathrm{Cl})^{*}$ \\
\hline \multicolumn{5}{|l|}{ GSE7390 } \\
\hline QI & Reference & Reference & Reference & Reference \\
\hline Q2 & $1.26(0.66-2.4 I)$ & $1.17(0.62-2.26)$ & $1.07(0.43-2.70)$ & I.0I (0.40-2.56) \\
\hline Q3 & $1.95(1.09-3.64)^{* *}$ & $2.00(1.06-3.85)^{* *}$ & $2.54(1.20-5.86)^{* *}$ & $2.45(1.09-5.88)$ \\
\hline Q4 & $1.68(0.91-3.19)$ & $1.93(0.91-4.16)$ & $2.04(0.92-4.82)$ & $1.75(0.66-4.82)$ \\
\hline \multicolumn{5}{|l|}{ GSEI 456} \\
\hline QI & Reference & Reference & Reference & Reference \\
\hline Q2 & $3.74(1.15-16.7)^{* *}$ & $4.14(1.01-27.9)^{* *}$ & $3.32(0.76-22.7)$ & $2.87(0.65-19.8)$ \\
\hline Q3 & $4.06(1.27-17.9)^{* *}$ & $5.21(1.24-35.6)^{* *}$ & $8.21(2.29-52.3)^{\ddagger}$ & $6.22(|.58-4| .5)^{\ddagger}$ \\
\hline Q4 & $6.62(2.20-28.5)^{\ddagger}$ & $7.52(1.81-52.0)^{\ddagger}$ & $11.9(3.43-74.9)^{\ddagger}$ & $7.55(1.87-51.4)^{\ddagger}$ \\
\hline \multicolumn{5}{|l|}{ GSE2034 } \\
\hline QI & $N / A$ & $N / A$ & Reference & Reference \\
\hline Q2 & $N / A$ & $N / A$ & $1.60(0.89-2.96)$ & $1.62(0.90-2.99)$ \\
\hline Q3 & $\mathrm{N} / \mathrm{A}$ & $N / A$ & $1.91(1.01-3.49)^{* *}$ & $1.97(1.10-3.6 \mathrm{I})^{* *}$ \\
\hline Q4 & $N / A$ & $N / A$ & $2.20(1.25-3.99)^{\ddagger}$ & $2.40(1.32-4.46)^{\ddagger}$ \\
\hline \multicolumn{5}{|l|}{ GSE4922 } \\
\hline QI & $\mathrm{N} / \mathrm{A}$ & $N / A$ & Reference & Reference \\
\hline Q2 & $N / A$ & $N / A$ & $1.27(0.63-2.62)$ & $1.19(0.58-2.47)$ \\
\hline Q3 & $N / A$ & $N / A$ & $2.17(1.15-4.29)^{* *}$ & $1.94(1.00-3.91)^{* *}$ \\
\hline Q4 & $N / A$ & $N / A$ & $3.43(1.87-6.63)^{\ddagger}$ & $2.88(1.43-6.03)^{\ddagger}$ \\
\hline \multicolumn{5}{|l|}{ NKI set } \\
\hline QI & Reference & Reference & Reference & Reference \\
\hline Q2 & $3.25(1.24-10.1)^{* *}$ & $2.61(0.99-8.14)$ & $1.85(0.98-3.60)$ & $1.59(0.84-3.12)^{* *}$ \\
\hline Q3 & $6.87(2.86-20.4)^{\ddagger}$ & $4.52(1.84-13.6)^{\ddagger}$ & $3.52(1.97-6.62)^{\ddagger}$ & $2.63(1.44-5.03)^{\ddagger}$ \\
\hline Q4 & $8.50(3.63-24.8)^{\ddagger}$ & $4.14(1.67-12.6)^{\ddagger}$ & $3.63(2.05-6.77)^{\ddagger}$ & $2.52(1.34-4.94)^{\ddagger}$ \\
\hline \multicolumn{5}{|l|}{ GSEI 0885} \\
\hline QI & Reference & Reference & Reference & Reference \\
\hline Q2 & I.72(0.57-5.35) & $1.14(0.32-3.93)$ & $1.45(0.59-3.56)$ & $1.23(0.44-3.34)$ \\
\hline Q3 & $2.8 \mathrm{I}(1.13-7.95)^{* *}$ & $2.28(0.88-6.64)$ & $2.5 \mathrm{I}(1.18-5.68)^{* *}$ & $2.58(1.11-6.40)^{* *}$ \\
\hline Q4 & $3.95(1.68-10.8)^{\ddagger}$ & $2.67(0.99-8.15)$ & $3.20(1.54-7.11)^{\ddagger}$ & $2.68(1.10-7.02)^{* *}$ \\
\hline \multicolumn{5}{|l|}{ GSE24450 } \\
\hline QI & Reference & & Reference & \\
\hline Q2 & $1.07(0.28-4.33)$ & $\mathrm{N} / \mathrm{A}$ & I.I4 (0.30-4.59) & N/A \\
\hline Q3 & $2.44(0.82-8.89)$ & $N / A$ & $2.83(0.94-10.3)$ & $N / A$ \\
\hline Q4 & $5.17(1.93-17.9)^{\ddagger}$ & $N / A$ & $5.73(2.13-19.8)^{\ddagger}$ & $N / A$ \\
\hline \multicolumn{5}{|l|}{ GSE22226 } \\
\hline QI & Reference & Reference & Reference & Reference \\
\hline Q2 & $0.99(0.27-3.56)$ & $0.91(0.24-3.71)$ & $1.32(0.49-3.69)$ & $1.01(0.33-3.17)$ \\
\hline Q3 & $1.80(0.62-5.87)$ & $1.58(0.50-5.98)$ & $2.21(0.92-5.82)$ & $2.08(0.82-5.96)$ \\
\hline Q4 & $1.73(0.58-5.73)$ & $1.25(0.37-4.84)$ & $1.55(0.60-4.28)$ & $1.25(0.44-3.78)$ \\
\hline \multicolumn{5}{|l|}{ GSE25066 } \\
\hline QI & & & Reference & Reference \\
\hline Q2 & $N / A$ & $N / A$ & $2.27(0.94-5.98)$ & $\mathrm{I} .86(0.74-5.0 \mathrm{I})$ \\
\hline Q3 & $N / A$ & $N / A$ & $2.00(0.82-5.32)$ & $\mathrm{I} .35(0.5 \mathrm{I}-3.8 \mathrm{I})$ \\
\hline Q4 & $N / A$ & $N / A$ & $1.63(0.64-4.44)$ & $0.97(0.36-2.8 \mathrm{I})$ \\
\hline \multicolumn{5}{|l|}{ GSE22220 } \\
\hline QI & & & Reference & Reference \\
\hline Q2 & $N / A$ & $N / A$ & $2.59(1.12-6.69)^{* *}$ & $2.26(0.86-7.05)$ \\
\hline Q3 & $N / A$ & $N / A$ & $4.91(2.26-12.24)^{\ddagger}$ & $4.80(1.90-|4.7|)^{\ddagger}$ \\
\hline Q4 & $N / A$ & $N / A$ & $6.54(3.05-16.18)^{\ddagger}$ & $7.38(2.90-22.75)^{\ddagger}$ \\
\hline \multicolumn{5}{|l|}{ GSE5303I } \\
\hline QI & & & Reference & Reference \\
\hline Q2 & $\mathrm{N} / \mathrm{A}$ & $\mathrm{N} / \mathrm{A}$ & $2.06(0.7 \mathrm{I}-6.73)$ & $1.86(0.64-6.09)$ \\
\hline Q3 & $\mathrm{N} / \mathrm{A}$ & $N / A$ & $3.45(1.36-10.49)^{\ddagger}$ & $2.67(1.01-8.40)^{* *}$ \\
\hline Q4 & $N / A$ & $N / A$ & $2.58(0.93-8.23)$ & $2.18(0.76-7.20)$ \\
\hline \multicolumn{5}{|l|}{ GSE588I 2} \\
\hline QI & Reference & Reference & Reference & Reference \\
\hline
\end{tabular}


Table 3 (Continued)

\begin{tabular}{|c|c|c|c|c|}
\hline \multirow[t]{2}{*}{ Data set } & \multicolumn{2}{|l|}{ Overall survival } & \multicolumn{2}{|c|}{ Progression-free survival } \\
\hline & HR (95\% Cl) & Adjusted HR $(95 \% \mathrm{Cl}) *$ & HR (95\% Cl) & Adjusted HR $(95 \% \mathrm{CI}) *$ \\
\hline Q2 & $2.76(0.92-10.05)$ & $3.49(1.16-12.79)^{* *}$ & $2.24(0.80-7.20)$ & $2.65(0.94-8.56)$ \\
\hline Q3 & $2.86(0.96-10.45)$ & $4.35(1.44-15.97)^{\ddagger}$ & $2.54(0.92-8.07)$ & $3.48(1.25-11.15)^{* *}$ \\
\hline Q4 & $1.25(0.33-5.07)$ & $1.74(0.46-7.05)$ & $1.01(0.28-3.64)$ & $1.32(0.36-4.77)$ \\
\hline \multicolumn{5}{|c|}{ Pooled data } \\
\hline Q I & Reference & Reference & Reference & Reference \\
\hline Q2 & $1.79(1.19-2.72)^{\ddagger}$ & I.3I (0.78-2.25) & $1.59(1.24-2.04)^{\ddagger}$ & $1.4 \mathrm{I}(1.04-1.9 \mathrm{I})^{* *}$ \\
\hline Q3 & $3.16(2.18-4.69)^{\ddagger}$ & $2.45(1.54-4.04)^{\ddagger}$ & $2.45(1.94-3.10)^{\ddagger}$ & $2.14(1.6 \mathrm{I}-2.88)^{\ddagger}$ \\
\hline Q4 & $3.80(2.65-5.60)^{\ddagger}$ & $2.03(1.24-3.42)^{\ddagger}$ & $2.71(2.16-3.43)^{\ddagger}$ & $1.94(1.43-2.64)^{\ddagger}$ \\
\hline
\end{tabular}

Notes: Univariate and multivariate analyses were conducted to evaluate HR of KIF4A (high vs low). *For multivariate analysis, HR was adjusted by age, ER status, Elston grade in GSE7390 and GSE10885, GSE22226, GSE24450, GSE25066, GSE22220, and GSE5303I. In the GSE4922 set, HR was adjusted by age. In the GSEI456 set, it was adjusted by Elston grade and ER status. For the GSE2034 set, HR was adjusted by ER status. The NKI set was adjusted by age, grade, and ER status. In the GSE588I 2 data set, HR was adjusted by age and ER status. HR was adjusted by age, ER status, and Elston grade in the pooled analysis. Statistical significance, $* * P<0.05 ; \neq P<0.01$.

Abbreviations: HR, hazard ratio; ER, estrogen receptor; KIF4A, human kinesin family member 4A; GEO, Gene Expression Omnibus; N/A, not applicable.

\section{Discussion}

In spite of advanced therapeutic techniques, breast cancer still remains the major cause of female deaths and continues to increase public health care expenditure. Breast cancer is a heterogeneous group of diseases which can be classified into four major molecular subtypes according to the expression of ER, progesterone receptor (PR), human epidermal growth factor receptor 2, and marker of proliferation Ki67 (MKI67). ${ }^{47-49}$ At present, outcomes of patients with breast cancer are predicted primarily on the basis of this classification and conventional clinicopathological characteristics such as histological grade, histological type, and TNM stage. In clinical practice, however, tumor heterogeneity always causes tremendous difficulty for the prediction of treatment response and prognosis. Researches on molecular mechanisms implicated in the biological process of breast cancer have obtained immense progress in the past few years. Various genetic changes have been identified to play critical roles in breast carcinogenesis and progress, ${ }^{50-52}$ but are merely the tip of the iceberg. Therefore, more effective molecular biomarkers are required to be further explored for breast cancer prevention, diagnosis, and treatment.

The results of our study revealed a strong and positive correlation between KIF4A expression and malignant features of breast cancer. We also found that KIF4A could serve as a robust prognostic predictor for both ER-negative and ERpositive breast cancers with prognostic power comparable to or even better than tumor size, lymph node invasion, and Elston grade. It is well known that chromosomal abnormality which can usually be caused by abnormal mitosis is a feature

Table 4 Univariate and multivariate analyses for KIF4A and survival in TCGA data sets

\begin{tabular}{|c|c|c|c|c|}
\hline \multirow[t]{2}{*}{ Data set } & \multicolumn{2}{|l|}{ Overall survival } & \multicolumn{2}{|c|}{ Progression-free survival } \\
\hline & HR (95\% Cl) & Adjusted HR (95\% Cl)* & HR (95\% CI) & Adjusted HR $(95 \% \mathrm{Cl}) *$ \\
\hline \multicolumn{5}{|l|}{ Data set I } \\
\hline QI & Reference & Reference & Reference & Reference \\
\hline Q2 & $0.73(0.38-1.37)$ & $0.85(0.44-1.60)$ & $1.37(0.66-2.90)$ & $\mathrm{I} .53(0.72-3.3 \mathrm{I})$ \\
\hline Q3 & $1.05(0.58-1.87)$ & $1.25(0.67-2.29)$ & $1.40(0.65-3.02)$ & $|.4|(0.63-3.21)$ \\
\hline Q4 & $0.97(0.55-1.72)$ & $1.10(0.58-2.08)$ & $1.27(0.59-2.73)$ & $1.14(0.50-2.61)$ \\
\hline \multicolumn{5}{|l|}{ Data set 2} \\
\hline QI & Reference & Reference & $\mathrm{N} / \mathrm{A}$ & $N / A$ \\
\hline Q2 & $1.89(1.45-2.48)^{\ddagger}$ & $1.82(1.39-2.39)^{\ddagger}$ & $\mathrm{N} / \mathrm{A}$ & N/A \\
\hline Q3 & $2.89(2.24-3.75)^{\ddagger}$ & $2.73(2.12-3.55)^{\ddagger}$ & N/A & $N / A$ \\
\hline Q4 & $2.93(2.28-3.80)^{\ddagger}$ & $2.57(1.97-3.38)^{\ddagger}$ & N/A & $N / A$ \\
\hline \multicolumn{5}{|c|}{ Pooled data } \\
\hline QI & Reference & Reference & Reference & Reference \\
\hline Q2 & $1.61(1.26-2.05)^{\ddagger}$ & $1.56(1.23-2.00)^{\ddagger}$ & $1.37(0.66-2.90)$ & $1.53(0.72-3.31)$ \\
\hline Q3 & $2.45(1.95-3.09)^{\ddagger}$ & $2.34(1.85-2.96)^{\ddagger}$ & $1.40(0.65-3.02)$ & $\mathrm{I} .4 \mathrm{I}(0.63-3.2 \mathrm{I})$ \\
\hline Q4 & $2.47(1.97-3.12)^{\ddagger}$ & $2.21(1.73-2.82)^{\ddagger}$ & $1.27(0.59-2.73)$ & $1.14(0.50-2.61)$ \\
\hline
\end{tabular}

Notes: Univariate and multivariate analyses were conducted to evaluate HR of KIF4A (high vs low). *For multivariate analysis, HR was adjusted by age and ER status in data set I, data set 2 , and pooled analysis. Statistical significance, ${ }^{\ddagger} P<0.0 \mathrm{I}$.

Abbreviations: HR, hazard ratio; ER, estrogen receptor; KIF4A, human kinesin family member 4A; TCGA, Cancer Genome Atlas; N/A, not applicable. 
A

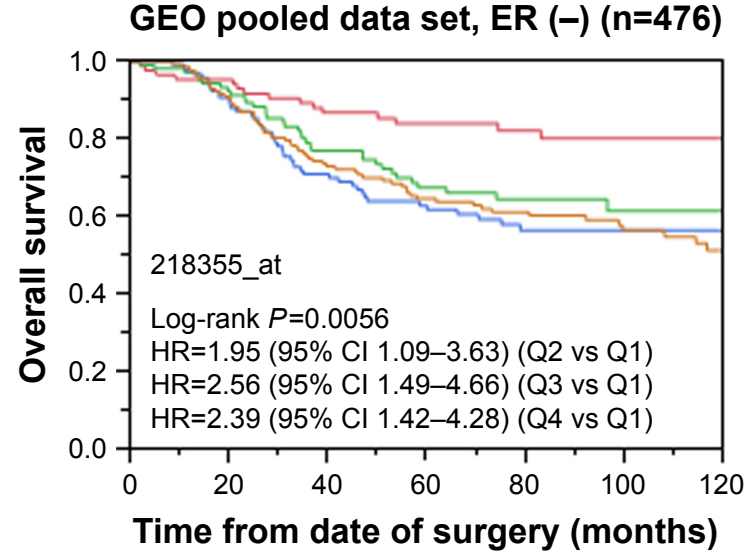

B

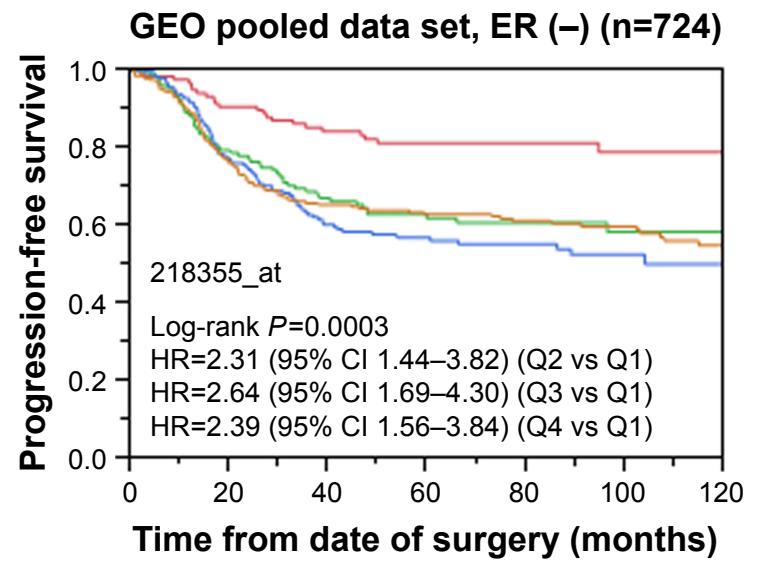

mRNA levels

$\begin{array}{llll}\mathrm{Q} 1-87 & 80 & 69 & 56 \\ \mathrm{Q} 2-108 & 95 & 71 & 55 \\ \mathrm{Q} 3-121 & 104 & 77 & 58 \\ \mathrm{Q} 4-160 & 138 & 106 & 80\end{array}$

C

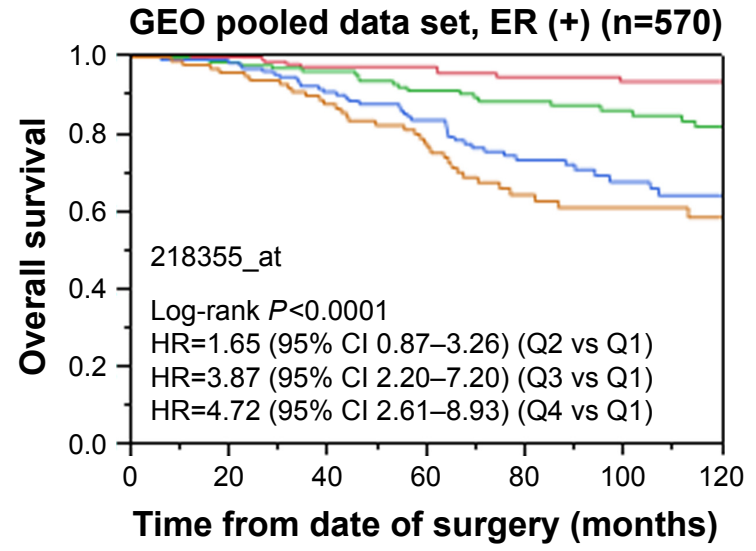

mRNA levels

$\begin{array}{lllllll}\mathrm{Q} 1-120 & 106 & 88 & 69 & 55 & 26 & 15 \\ \mathrm{Q} 2-335 & 299 & 244 & 201 & 150 & 110 & 80 \\ \mathrm{Q} 3-302 & 263 & 209 & 154 & 115 & 80 & 53 \\ \mathrm{Q} 4-215 & 168 & 123 & 91 & 68 & 53 & 39\end{array}$

D

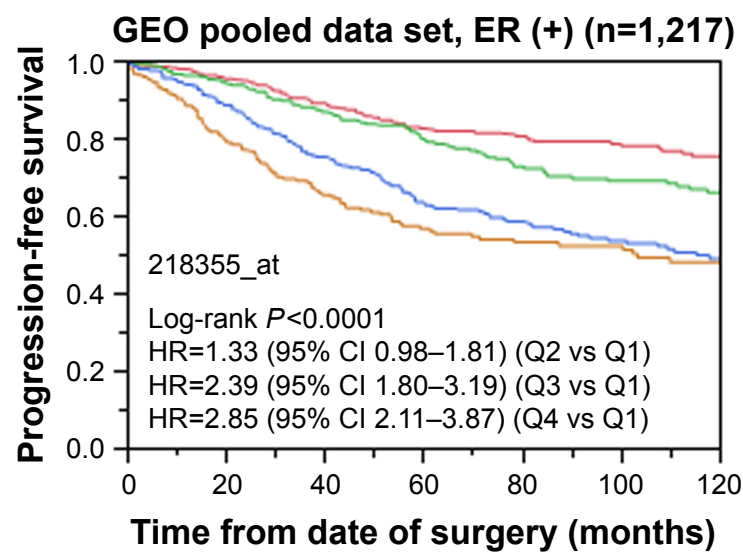

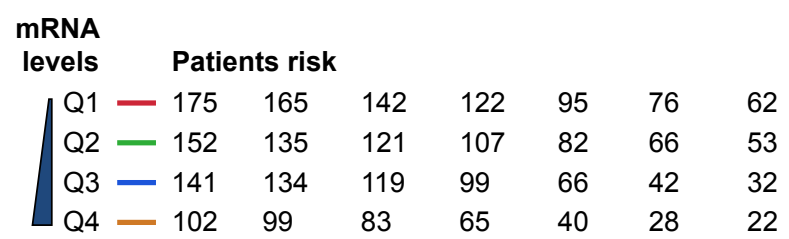

mRNA

levels Patients risk

$\begin{array}{lllllll}\text { Q1 }-365 & 338 & 280 & 222 & 181 & 135 & 99 \\ \text { Q2 - 335 } & 299 & 244 & 201 & 150 & 110 & 80 \\ \text { Q3 - 302 } & 263 & 209 & 154 & 115 & 80 & 53 \\ \text { Q4 - 215 } & 168 & 123 & 91 & 67 & 53 & 39\end{array}$

Figure 3 Prognostic performance of KIF4A in ER-positive and ER-negative breast cancer. mRNA levels of KIF4A and overall survival in (A) ER-negative, (C) ER-positive breast cancer in GEO pooled data set. mRNA levels of KIF4A and progression-free survival in (B) ER-negative, (D) ER-positive breast cancer in GEO pooled data set. Abbreviations: KIF4A, human kinesin family member 4A; GEO, Gene Expression Omnibus; ER, estrogen receptor; HR, hazard ratio.

of cancer cells. Previous studies have shown that KIF4A was closely associated with the regulation of chromosome structural integrity, spindle midzone formation, and cytokinesis. ${ }^{8-11}$ It is reasonable to speculate that high KIF4A expression generates cells with chromosomal damage and therefore increases susceptibility to cancer. ${ }^{53}$ Additionally, KIF4A has been implicated as an important molecule leading to the failure of DNA repair through influencing the BRCA2/Rad51 pathway and inhibiting the enzymatic activity of PARP-1. 14,20,54 That means the higher the KIF4A expression level, the more the mitotic defects and DNA errors. Commonly, failure of DNA repair is associated with genomic instability which contributes 
significantly to drug resistance and tumor progression. This could be an explanation for the poor outcomes of breast cancer patients with high expression level of KIF4A.

We next embarked on a search to find the potential microRNAs targeting KIF4A mRNA expression. By using the GSE22220 data set and online miRanda algorithm, miR335 finally came to the fore. It is important to note that the expression of miR-335 was significantly associated with better PFS in a dose-dependent manner. In addition, the prognostic value of miR-335 was comparable with tumor size and lymph node involvement, better than Elston grade in ER-positive breast cancer. Results of the dual luciferase reporter assay indicated that the expression of KIF4A might be modulated by miR-335 through direct binding to the

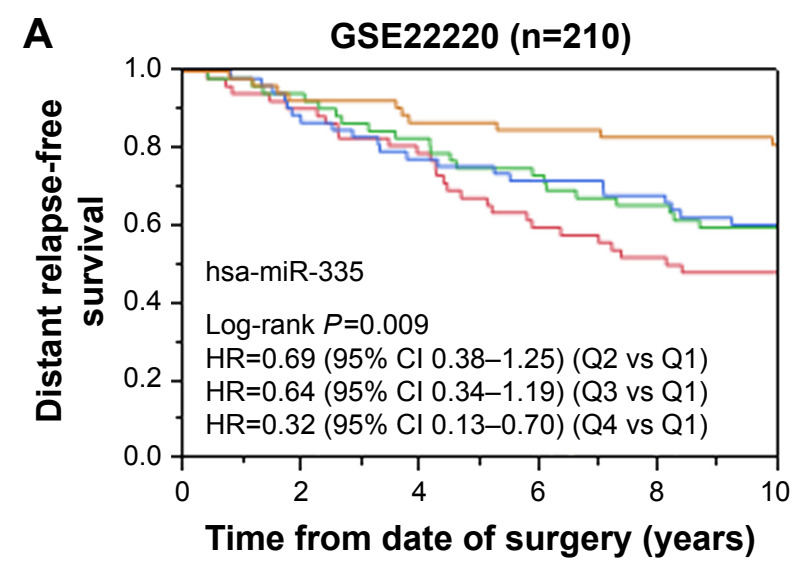
mRNA
levels \begin{tabular}{|llllll}
$\mathrm{Q} 1-52$ & 47 & 41 & 32 & 27 & 25 \\
$\mathrm{Q} 2-52$ & 49 & 43 & 38 & 34 & 31 \\
$\mathrm{Q} 3-52$ & 47 & 41 & 39 & 36 & 32 \\
$\mathrm{Q} 4-53$ & 50 & 47 & 45 & 44 & 41
\end{tabular}
3'-UTR of KIF4A mRNA. Accumulating evidence suggests that miR-335 may play an important role during tumor development. ${ }^{26,55,56}$ miR-335 was found to exert a tumorsuppressive function in breast cancer, ${ }^{55,57,58}$ lung cancer, ${ }^{59}$ pancreatic cancer, ${ }^{60}$ gastric cancer, ${ }^{61,62}$ ovarian cancer, ${ }^{63}$ renal cancer, ${ }^{26}$ prostate cancer, ${ }^{64}$ and malignant glioma. ${ }^{56}$ However, in astrocytoma ${ }^{65}$ and meningiomas, ${ }^{66}$ miR-335 acts as an oncogene. According to previous researches, the loss of miR-335 expression is a common event in human breast cancer which ultimately leads to tumor progression. ${ }^{57,67,68}$ miR-335 was found to inhibit breast cancer cell migration and invasion by directly targeting EphA4 ${ }^{55}$ and PAX6. ${ }^{69}$ A group of German researchers reported that miR-335 was crucial for the BRCA1 regulatory cascade in breast cancer

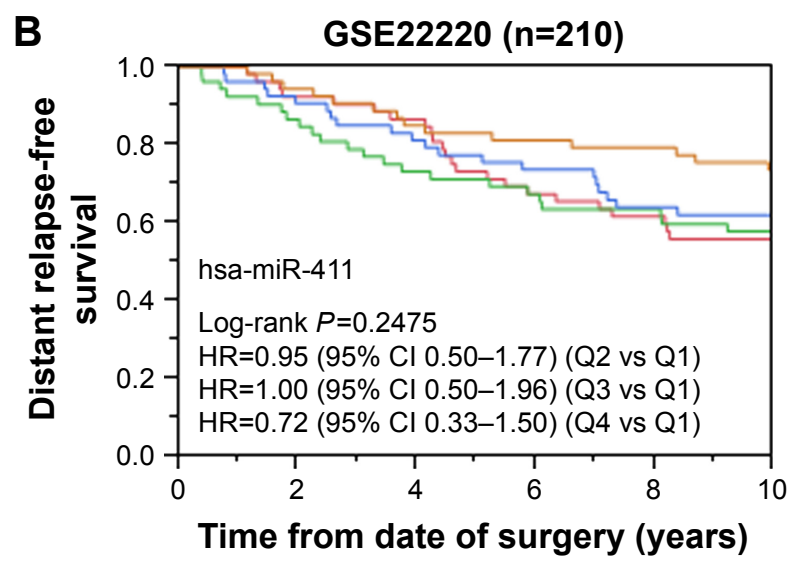

mRNA

$\begin{array}{ccccccc}\text { levels } & \text { Patients risk } & & & & \\ \text { Q1 }-52 & 49 & 45 & 35 & 32 & 29 \\ \text { Q2 }-52 & 45 & 38 & 35 & 33 & 30 \\ \text { Q3 - 52 } & 49 & 44 & 39 & 33 & 32 \\ \text { Q4 }-53 & 50 & 44 & 43 & 42 & 38\end{array}$

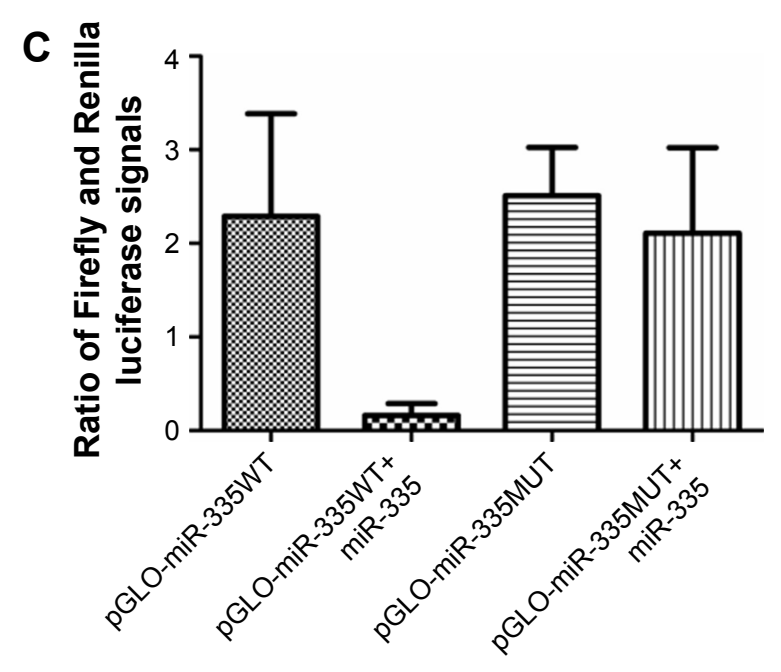

Figure 4 (Continued) 

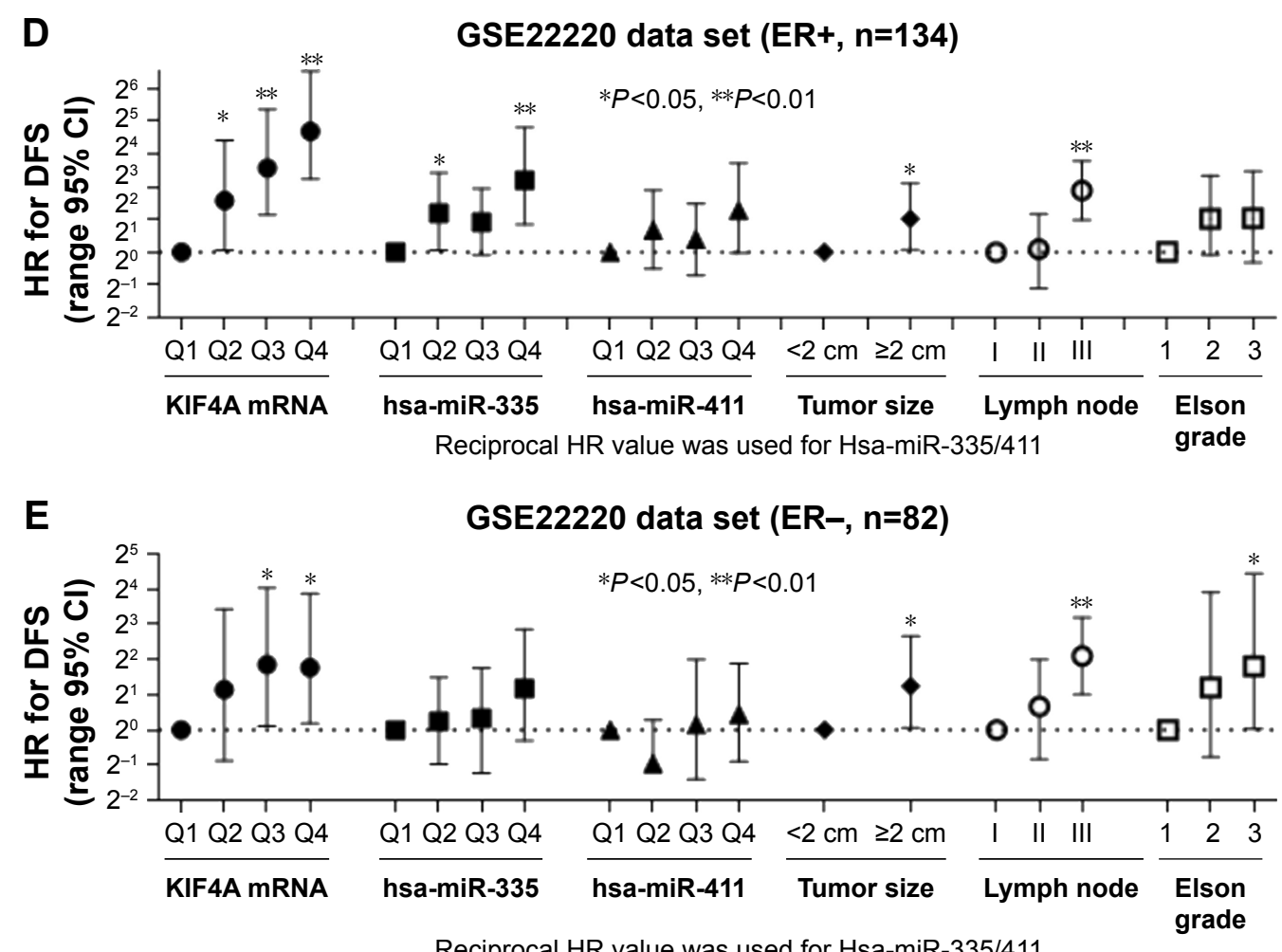

Reciprocal HR value was used for Hsa-miR-335/411

Figure 4 miR-335 associated with poor outcome of breast cancer by targeting the 3'-UTR of KIF4A mRNA. Overall survival analysis for miR-335 in GSE22220 data set with (A) overall survival information, (B) progression-free survival information. (C) Results of dual luciferase reporter assay. The prognostic performance of miR-335 in (D) ERpositive, (E) ER-negative breast cancer in GSE22220 data set.

Abbreviations: KIF4A, human kinesin family member 4A; miR, microRNA; UTR, untranslated region; ER, estrogen receptor; HR, hazard ratio; DFS, disease-free survival.

development. ${ }^{68}$ Results of these studies are consistent with our findings and support the view that downregulation of miR-335 may be associated with poor prognosis in patients with breast cancer. For the first time, we linked the expression of KIF4A to miR-335, which may help us to better understand the underlying mechanisms by which KIF4A influences breast cancer progression, and may lead to the identification and development of novel therapeutic targets.

A

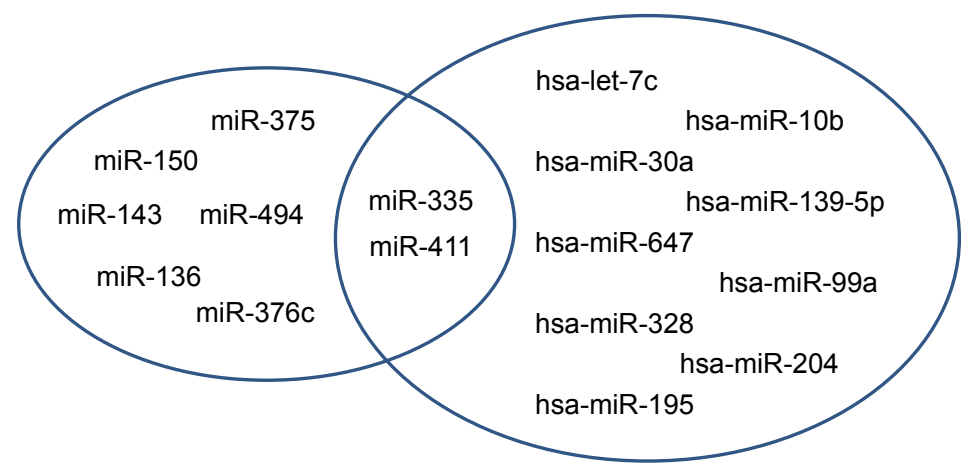

B hsa-miR-335/KIF4A alignment

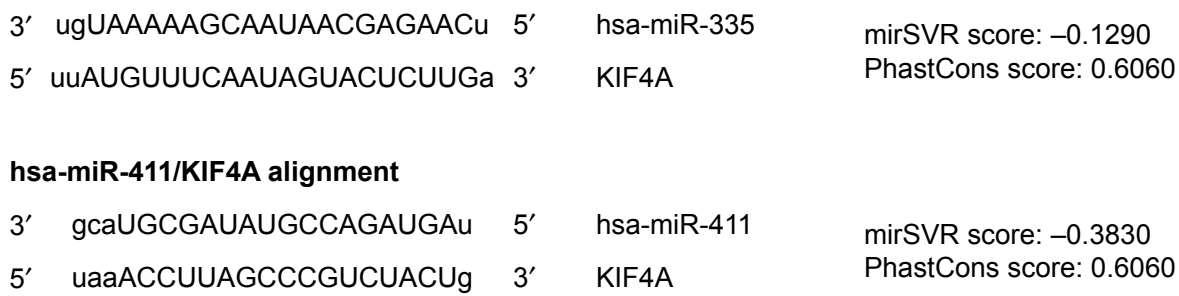

Figure 5 (Continued) 

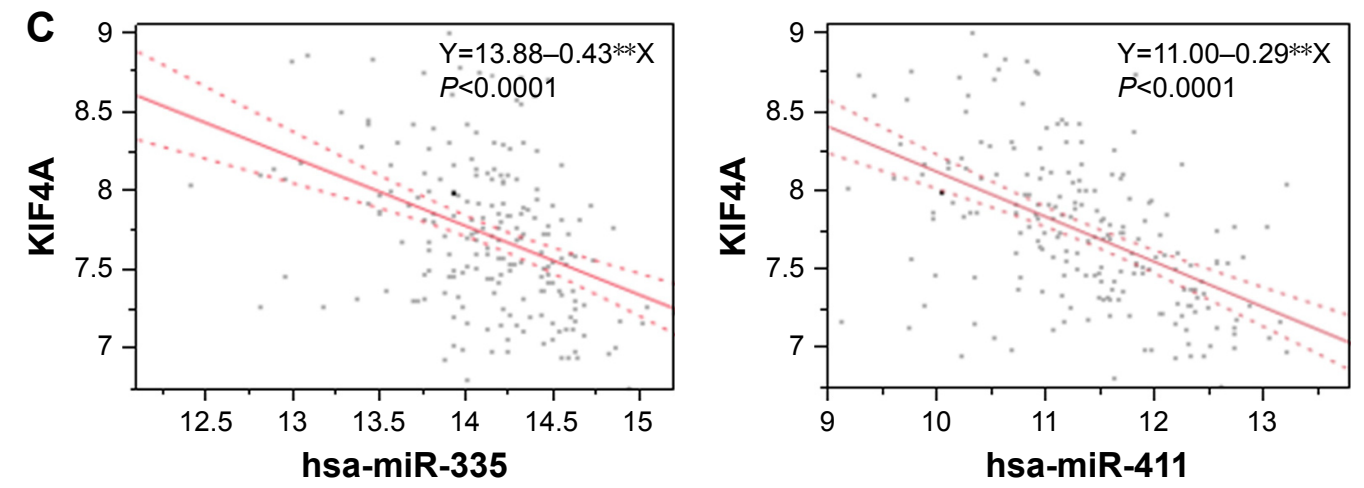

Figure 5 miR-335 and miR-4II are possible regulators of KIF4A. (A) Correlation between KIF4A and miR. (B) The predicted binding sequence of miR-335/miR-4II and KIF4A mRNA 3'-UTR, along with the thermodynamic stability score (mirSVR) and sequence conservation score (PhastCons). (C) The level of KIF4A in breast cancer was negatively correlated with miR-335 and miR-4II expression.

Abbreviations: KIF4A, human kinesin family member 4A; miR, microRNA; UTR, untranslated region; mirSVR, miRNA support vector regression.

\section{Limitations}

There are several limitations in the current study. First, it is primarily a data sets analysis without further confirmation by clinical tissue samples which decrease the robustness of our conclusions. Second, except the dual luciferase reporter assay, we did not perform any other experiments to uncover the detailed molecular biological mechanisms by which KIF4A affects the prognosis of breast cancer. Thus, there is still plenty of work to be done to make the whole story complete.

\section{Conclusion}

Our findings suggested that KIF4A may have strong prognostic value for predicting clinical outcome in different breast cancer subgroups, which may contribute to the direct regulation of miR-335. Targeting KIF4A activity could be a promising therapeutic option in breast cancer treatment. In view of its crucial significance and potential clinical value, a thorough study into it is worth the effort.

\section{Acknowledgment}

We gratefully acknowledge the financial support from the Natural Science Foundation of Zhejiang Province (LY18H160001) and National Natural Science Foundation of China (81702803).

\section{Disclosure}

The authors report no conflicts of interest in this work.

\section{References}

1. Siegel RL, Miller KD, Jemal A. Cancer statistics, 2017. CA Cancer J Clin. 2017;67(1):7-30.

2. Miller KD, Siegel RL, Lin CC, et al. Cancer treatment and survivorship statistics, 2016. CA Cancer J Clin. 2016;66(4):271-289.
3. Paterson R, Phillips KA. Genetic testing in women with breast cancer: implications for treatment. Expert Rev Anticancer Ther. 2017;17(11): 991-1002.

4. Katanoda K, Matsuda T. Five-year relative survival rate of breast cancer in the USA, Europe and Japan. Jpn J Clin Oncol. 2014;44(6):611.

5. Chang HY, Nuyten DS, Sneddon JB, et al. Robustness, scalability, and integration of a wound-response gene expression signature in predicting breast cancer survival. Proc Natl Acad Sci U S A. 2005;102(10):3738-3743.

6. Puhalla SL, Davidson NE. Breast cancer: the 21-gene recurrence scorebiology remains at the forefront. Nat Rev Clin Oncol. 2016;13(8): 470-472.

7. van't Veer LJ, Dai H, van de Vijver MJ, et al. Gene expression profiling predicts clinical outcome of breast cancer. Nature. 2002;415(6871): 530-536.

8. Mazumdar M, Sundareshan S, Misteli T. Human chromokinesin KIF4A functions in chromosome condensation and segregation. $J$ Cell Biol. 2004;166(5):613-620.

9. Kurasawa Y, Earnshaw WC, Mochizuki Y, Dohmae N, Todokoro K. Essential roles of KIF4 and its binding partner PRC1 in organized central spindle midzone formation. EMBO J. 2004;23(16):3237-3248.

10. Zhu C, Jiang W. Cell cycle-dependent translocation of PRC1 on the spindle by Kif4 is essential for midzone formation and cytokinesis. Proc Natl Acad Sci U S A. 2005;102(2):343-348.

11. Hu CK, Coughlin M, Field CM, Mitchison TJ. KIF4 regulates midzone length during cytokinesis. Curr Biol. 2011;21(10):815-824.

12. Taniwaki M, Takano A, Ishikawa N, et al. Activation of KIF4A as a prognostic biomarker and therapeutic target for lung cancer. Clin Cancer Res. 2007;13(22 Pt 1):6624-6631.

13. Zhang L, Huang Q, Lou J, et al. A novel PHD-finger protein 14/KIF4A complex overexpressed in lung cancer is involved in cell mitosis regulation and tumorigenesis. Oncotarget. 2017;8(12):19684-19698.

14. Wang $\mathrm{H}, \mathrm{Lu} \mathrm{C}, \mathrm{Li}$ Q, et al. The role of Kif4A in doxorubicin-induced apoptosis in breast cancer cells. Mol Cells. 2014;37(11):812-818.

15. Narayan G, Bourdon V, Chaganti S, et al. Gene dosage alterations revealed by cDNA microarray analysis in cervical cancer: identification of candidate amplified and overexpressed genes. Genes Chromosomes Cancer. 2007;46(4):373-384.

16. Hou G, Dong C, Dong Z, et al. Upregulate KIF4A enhances proliferation, invasion of hepatocellular carcinoma and indicates poor prognosis across human cancer types. Sci Rep. 2017;7(1):4148.

17. Minakawa Y, Kasamatsu A, Koike H, et al. Kinesin family member 4A: a potential predictor for progression of human oral cancer. PLoS One. 2013;8(12):e85951.

18. Zhang Y, Liu S, Qu D, et al. Kif4A mediate the accumulation and reeducation of THP-1 derived macrophages via regulation of CCL2-CCR2 expression in crosstalking with OSCC. Sci Rep. 2017;7(1):2226. 
19. Gao J, Sai N, Wang C, et al. Overexpression of chromokinesin KIF4 inhibits proliferation of human gastric carcinoma cells both in vitro and in vivo. Tumour Biol. 2011;32(1):53-61.

20. Wu G, Zhou L, Khidr L, et al. A novel role of the chromokinesin Kif4A in DNA damage response. Cell Cycle. 2008;7(13):2013-2020.

21. Schickel R, Boyerinas B, Park SM, Peter ME. MicroRNAs: key players in the immune system, differentiation, tumorigenesis and cell death. Oncogene. 2008;27(45):5959-5974.

22. Chen X, Wu B, Xu Z, et al. Downregulation of miR-133b predict progression and poor prognosis in patients with urothelial carcinoma of bladder. Cancer Med. 2016;5(8):1856-1862.

23. Chen XN, Wang KF, Xu ZQ, et al. MiR-133b regulates bladder cancer cell proliferation and apoptosis by targeting Bcl-w and Akt1. Cancer Cell Int. 2014;14:70.

24. Bartel DP. MicroRNAs: genomics, biogenesis, mechanism, and function. Cell. 2004;116(2):281-297.

25. Farazi TA, Hoell JI, Morozov P, Tuschl T. MicroRNAs in human cancer. Adv Exp Med Biol. 2013;774:1-20.

26. Wang K, Chen X, Zhan Y, et al. miR-335 inhibits the proliferation and invasion of clear cell renal cell carcinoma cells through direct suppression of BCL-W. Tumour Biol. 2015;36(9):6875-6882.

27. Yates LA, Norbury CJ, Gilbert RJ. The long and short of microRNA. Cell. 2013;153(3):516-519.

28. Dassow H, Aigner A. MicroRNAs (miRNAs) in colorectal cancer: from aberrant expression towards therapy. Curr Pharm Des. 2013;19(7):1242-1252.

29. Zhang B, Pan X, Cobb GP, Anderson TA. microRNAs as oncogenes and tumor suppressors. Dev Biol. 2007;302(1):1-12.

30. Barbato S, Solaini G, Fabbri M. MicroRNAs in oncogenesis and tumor suppression. Int Rev Cell Mol Biol. 2017;333:229-268.

31. Fang Y, Zhang L, Li Z, Li Y, Huang C, Lu X. MicroRNAs in DNA damage response, carcinogenesis, and chemoresistance. Int Rev Cell Mol Biol. 2017;333:1-49.

32. Lee GY, Haverty PM, Li L, et al. Comparative oncogenomics identifies PSMB4 and SHMT2 as potential cancer driver genes. Cancer Res. 2014;74(11):3114-3126.

33. Tomczak K, Czerwinska P, Wiznerowicz M. The Cancer Genome Atlas (TCGA): an immeasurable source of knowledge. Contemp Oncol (Pozn). 2015;19(1A):A68-A77.

34. Desmedt C, Piette F, Loi S, et al. Strong time dependence of the 76-gene prognostic signature for node-negative breast cancer patients in the TRANSBIG multicenter independent validation series. Clin Cancer Res. 2007;13(11):3207-3214.

35. Smeds J, Miller LD, Bjohle J, et al. Gene profile and response to treatment. Ann Oncol. 2005;16 Suppl 2:195-202.

36. Wang Y, Klijn JG, Zhang Y, et al. Gene-expression profiles to predict distant metastasis of lymph-node-negative primary breast cancer. Lancet. 2005;365(9460):671-679.

37. Ivshina AV, George J, Senko O, et al. Genetic reclassification of histologic grade delineates new clinical subtypes of breast cancer. Cancer Res. 2006;66(21):10292-10301.

38. van de Vijver MJ, He YD, van't Veer LJ, et al. A gene-expression signature as a predictor of survival in breast cancer. $N$ Engl J Med. 2002;347(25):1999-2009.

39. Hennessy BT, Gonzalez-Angulo AM, Stemke-Hale K, et al. Characterization of a naturally occurring breast cancer subset enriched in epithelial-to-mesenchymal transition and stem cell characteristics. Cancer Res. 2009;69(10):4116-4124.

40. Muranen TA, Greco D, Fagerholm R, et al. Breast tumors from CHEK2 1100delC-mutation carriers: genomic landscape and clinical implications. Breast Cancer Res. 2011;13(5):R90.

41. Esserman LJ, Berry DA, Cheang MC, et al. Chemotherapy response and recurrence-free survival in neoadjuvant breast cancer depends on biomarker profiles: results from the I-SPY 1 TRIAL (CALGB 150007/150012; ACRIN 6657). Breast Cancer Res Treat. 2012;132(3):1049-1062.

42. Hatzis C, Pusztai L, Valero V, et al. A genomic predictor of response and survival following taxane-anthracycline chemotherapy for invasive breast cancer. JAMA. 2011;305(18):1873-1881.
43. Azim HA Jr, Brohee S, Peccatori FA, et al. Biology of breast cancer during pregnancy using genomic profiling. Endocr Relat Cancer. 2014;21(4):545-554.

44. Jezequel P, Loussouarn D, Guerin-Charbonnel C, et al. Gene-expression molecular subtyping of triple-negative breast cancer tumours: importance of immune response. Breast Cancer Res. 2015;17:43.

45. Buffa FM, Camps C, Winchester L, et al. microRNA-associated progression pathways and potential therapeutic targets identified by integrated mRNA and microRNA expression profiling in breast cancer. Cancer Res. 2011;71(17):5635-5645.

46. Subramanian A, Tamayo P, Mootha VK, et al. Gene set enrichment analysis: a knowledge-based approach for interpreting genome-wide expression profiles. Proc Natl Acad Sci U S A. 2005;102(43):15545-15550.

47. Sorlie T, Tibshirani R, Parker J, et al. Repeated observation of breast tumor subtypes in independent gene expression data sets. Proc Natl Acad Sci U S A. 2003;100(14):8418-8423.

48. Sorlie T, Wang Y, Xiao C, et al. Distinct molecular mechanisms underlying clinically relevant subtypes of breast cancer: gene expression analyses across three different platforms. BMC Genomics. 2006;7:127.

49. Goldhirsch A, Wood WC, Coates AS, et al. Strategies for subtypes dealing with the diversity of breast cancer: highlights of the St. Gallen International Expert Consensus on the Primary Therapy of Early Breast Cancer 2011. Ann Oncol. 2011;22(8):1736-1747.

50. Buys SS, Sandbach JF, Gammon A, et al. A study of over 35,000 women with breast cancer tested with a 25 -gene panel of hereditary cancer genes. Cancer. 2017;123(10):1721-1730.

51. Li G, Guo X, Tang L, et al. Analysis of BRCA1/2 mutation spectrum and prevalence in unselected Chinese breast cancer patients by next-generation sequencing. J Cancer Res Clin Oncol. 2017;143(10):2011-2024.

52. Cybulski C, Carrot-Zhang J, Kluzniak W, et al. Germline RECQL mutations are associated with breast cancer susceptibility. Nat Genet. 2015;47(6):643-646.

53. Borysov SI, Granic A, Padmanabhan J, Walczak CE, Potter H. Alzheimer $\mathrm{A} \beta$ disrupts the mitotic spindle and directly inhibits mitotic microtubule motors. Cell Cycle. 2011;10(9):1397-1410.

54. Midorikawa R, Takei Y, Hirokawa N. KIF4 motor regulates activitydependent neuronal survival by suppressing PARP-1 enzymatic activity. Cell. 2006;125(2):371-383.

55. Dong Y, Liu Y, Jiang A, Li R, Yin M, Wang Y. MicroRNA-335 suppresses the proliferation, migration, and invasion of breast cancer cells by targeting EphA4. Mol Cell Biochem. 2018;439(1-2):95-104.

56. Shu M, Zhou Y, Zhu W, et al. MicroRNA 335 is required for differentiation of malignant glioma cells induced by activation of cAMP/protein kinase A pathway. Mol Pharmacol. 2012;81(3):292-298.

57. Tavazoie SF, Alarcon C, Oskarsson T, et al. Endogenous human microRNAs that suppress breast cancer metastasis. Nature. 2008; 451(7175):147-152.

58. Gao Y, Zeng F, Wu JY, et al. MiR-335 inhibits migration of breast cancer cells through targeting oncoprotein c-Met. Tumour Biol. 2015;36(4): 2875-2883.

59. Wang H, Li M, Zhang R, et al. Effect of miR-335 upregulation on the apoptosis and invasion of lung cancer cell A549 and H1299. Tumour Biol. 2013;34(5):3101-3109.

60. Gao L, Yang Y, Xu H, et al. MiR-335 functions as a tumor suppressor in pancreatic cancer by targeting OCT4. Tumour Biol. 2014;35(8):8309-8318.

61. Li H, Zhu H, Zhou Y, et al. Long non-coding RNA MSTO2P promotes the proliferation and colony formation in gastric cancer by indirectly regulating miR-335 expression. Tumour Biol. 2017; 39(6):1010428317705506.

62. Yan Z, Xiong Y, Xu W, et al. Identification of hsa-miR-335 as a prognostic signature in gastric cancer. PLoS One. 2012;7(7):e40037.

63. Sorrentino A, Liu CG, Addario A, Peschle C, Scambia G, Ferlini C. Role of microRNAs in drug-resistant ovarian cancer cells. Gynecol Oncol. 2008;111(3):478-486.

64. Xiong SW, Lin TX, Xu KW, et al. MicroRNA-335 acts as a candidate tumor suppressor in prostate cancer. Pathol Oncol Res. 2013; 19(3):529-537. 
65. Shu M, Zheng X, Wu S, et al. Targeting oncogenic miR-335 inhibits growth and invasion of malignant astrocytoma cells. Mol Cancer. 2011;10:59.

66. Shi L, Jiang D, Sun G, et al. miR-335 promotes cell proliferation by directly targeting Rb1 in meningiomas. J Neurooncol. 2012; 110(2):155-162.

67. Png KJ, Yoshida M, Zhang XH, et al. MicroRNA-335 inhibits tumor reinitiation and is silenced through genetic and epigenetic mechanisms in human breast cancer. Genes Dev. 2011;25(3):226-231.
68. Heyn H, Engelmann M, Schreek S, et al. MicroRNA miR-335 is crucial for the BRCA1 regulatory cascade in breast cancer development. Int $J$ Cancer. 2011;129(12):2797-2806.

69. Meng Y, Zou Q, Liu T, Cai X, Huang Y, Pan J. microRNA-335 inhibits proliferation, cell-cycle progression, colony formation, and invasion via targeting PAX6 in breast cancer cells. Mol Med Rep. 2015; 11(1):379-385.

\section{Publish your work in this journal}

OncoTargets and Therapy is an international, peer-reviewed, open access journal focusing on the pathological basis of all cancers, potential targets for therapy and treatment protocols employed to improve the management of cancer patients. The journal also focuses on the impact of management programs and new therapeutic agents and protocols on

\section{Dovepress}

patient perspectives such as quality of life, adherence and satisfaction. The manuscript management system is completely online and includes a very quick and fair peer-review system, which is all easy to use. Visit http://www.dovepress.com/testimonials.php to read real quotes from published authors.

Submit your manuscript here: http://www.dovepress.com/oncotargets-and-therapy-journal 